\title{
Competencia digital en niños de educación básica del sureste de México
}

\section{Digital competences of children in basic education in southeastern Mexico}

\section{Competência digital em crianças na educação básica no sudeste do México}

Sergio Humberto Quiñonez Pech

Universidad Autónoma de Yucatán, México sergio.quinonez@correo.uady.mx https://orcid.org/0000-0001-5220-9912

\author{
Alfredo Zapata González \\ Universidad Autónoma de Yucatán, México \\ zgonza@correo.uady.mx \\ https://orcid.org/0000-0001-5087-6244 \\ Pedro José Canto Herrera \\ Universidad Autónoma de Yucatán, México \\ pcanto@correo.uady.mx \\ https://orcid.org/0000-0001-5428-8343
}

\section{Resumen}

El avance tecnológico y sus múltiples aplicaciones han creado condiciones para que las nuevas generaciones enfrenten retos y desarrollen aptitudes y actitudes vinculadas con el uso de las tecnologías de información y comunicación (TIC). Debido a ello, necesitan fortalecer nuevas competencias digitales para facilitar su inserción en la sociedad del conocimiento. En este estudio, se describen los resultados de una encuesta sobre la manera en que emplean las TIC los niños de educación básica del municipio de Mérida, ubicado en el sureste de México. Los participantes fueron 160 niños (53\% mujeres y $47 \%$ hombres). El estudio cuantitativo tipo encuesta tuvo un alcance descriptivo y transversal. Como principal resultado se evidenció que $78 \%$ de los niños poseen un dominio limitado con respecto al uso de las TIC, por lo que es necesario desarrollar en ellos competencias digitales, de modo que puedan empelar de forma responsable el Internet en sus actividades académicas.

Palabras clave: competencias digitales, educación básica, nativos digitales, TIC. 


\section{Abstract}

Technological progress and its multiple applications have created conditions for a generation that is constantly facing challenges, developing skills and attitudes related to the use of Information and Communication Technologies (ICT). The new generations need to strengthen their digital skills to facilitate their insertion into the knowledge society This article describes the results of a survey on the use of ICT by children in basic education in the municipality of Mérida in southeastern Mexico. The participants were 160 children (53\% were women and $47 \%$ men). The quantitative survey study was descriptive with a transversal scope. The main findings evidenced that $78 \%$ of children have a limited domain with respect to the use of ICT, it is necessary to develop their digital skills, including the responsible use of the Internet for their academic activities.

Keywords: digital skills, basic education, digital natives, ICT.

\section{Resumo}

O progresso tecnológico e suas múltiplas aplicações criaram condições para as novas gerações enfrentarem desafios e desenvolverem habilidades e atitudes relacionadas ao uso das tecnologias da informação e comunicação (TIC). Por isso, eles precisam fortalecer novas habilidades digitais para facilitar sua inserção na sociedade do conhecimento. Neste estudo, são descritos os resultados de uma pesquisa sobre como as TICs utilizadas por crianças no ensino fundamental no município de Mérida, localizado no sudeste do México, são descritas. Participaram 160 crianças (53\% mulheres e 47\% homens). O estudo do tipo quantitativo de pesquisa teve escopo descritivo e transversal. Como resultado principal, ficou evidenciado que $78 \%$ das crianças possuem um domínio limitado no que diz respeito ao uso das TIC, sendo necessário desenvolver habilidades digitais nelas, para que possam usar a Internet de forma responsável em suas atividades acadêmicas.

Palavras-chave: habilidades digitais, educação básica, nativos digitais, TIC.

Fecha Recepción: Julio 2019

Fecha Aceptación: Diciembre 2019 


\section{Revista Iberoamericana \\ de las Ciencias Sociales y \\ Humanísticas}

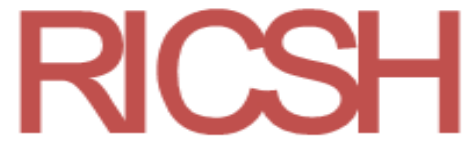

ISSN: 2395 - 7972

\section{Introducción}

En la actualidad, el uso de las TIC es un requerimiento indispensable para formarse, desenvolverse en el mundo laboral y acercarse a otras culturas y sociedades. Esta tendencia global ha hecho que México, a través de la Secretaría de Educación Pública (SEP), promueva distintos proyectos educativos que dotan de tecnología a las aulas de clase, entre los cuales se puede mencionar el programa COEEBA (Computación Electrónica en Educación Básica), caracterizado por promover talleres y laboratorios de computación para los profesores. Igualmente, se destaca el proyecto Red Escolar, implementado en 1996 con base en un modelo pedagógico que procuraba masificar el uso de las TIC en todos lo grados de primaria.

Más adelante, en 2004, se implementó el programa Enciclomedia, el cual proponía la digitalización de los libros de texto y estaba orientado a los niños de quinto y sexto grado de primaria. Luego, en 2009, se concretó el programa habilidades digitales para todos, iniciativa que impulsó el desarrollo de las tecnologías en escuelas de educación básica para apoyar el aprendizaje de los estudiantes, desarrollar sus competencias digitales y favorecer su inserción en la sociedad del conocimiento (SEP, 2009).

Posteriormente, en 2013, el Gobierno de México implementó dos iniciativas más: el programa piloto de inclusión digital en los estados de Morelos, Guanajuato y Querétaro (mediante el cual se otorgaban laptops a los estudiantes), y el programa MiCompu.mx en los estados de Sonora, Tabasco y Colima, el cual se enfocó en mejorar, mediante el uso y aprovechamiento del computador personal, las condiciones de estudio de los niños, la actualización de las formas de enseñanza, el fortalecimiento de los colectivos docentes, la revalorización de la escuela pública y la reducción de las brechas digitales y sociales entre las familias y las comunidades que integran el país (Linarez, 2014).

Asimismo, en 2014, el Proyecto de Inclusión y Alfabetización Digital (PIAD) del Gobierno de México entró en su segunda etapa dentro del programa @ prende.mx, en el cual se cambiaron las computadoras personales por tabletas. Esta iniciativa buscaba explorar nuevas vías para potenciar las habilidades digitales mediante el fomento del trabajo colaborativo en los salones de clases. En concreto, se pretendía que tanto los niños como los profesores aprovecharan de manera coordinada la tecnología digital para optimizar los procesos de enseñanza y aprendizaje (SEP, 2016). Este programa tenía como fin reducir la brecha digital, la cual se genera cuando solo un sector de la población cuenta con las herramientas y las habilidades para usar los recursos tecnológicos. Los beneficiarios de dicho programa fueron los estudiantes de quinto año de primaria, así como los profesores responsables de dichos grupos (SEP, 2016). En el caso del estado de Yucatán, las tabletas 


\section{Revista Iberoamericana \\ de las Ciencias Sociales y \\ Humanísticas}

ISSN: 2395 - 7972

fueron entregadas a municipios como Mérida, Tizimín, Valladolid, Ticul, Izamal y Peto.

Dichos dispositivos contaban con contenido académico precargado sobre temas tan diversos como nutrición, cuidado de datos personales, economía familiar, salud, zonas arqueológicas del país, entre otros (Gobierno del Estado de Yucatán, 2015).

Posteriormente, en 2017, se implementó la tercera fase del Programa de Inclusión y Alfabetización Digital de la SEP bajo el nombre de @ prende 2.0. Esta nueva versión del programa@ @rende.mx tomó en cuenta las experiencias internacionales respecto al uso de las tecnologías y dio cumplimiento a las cinco dimensiones definidas por la Unesco para lograr una educación de calidad; esas dimensiones fueron relevancia, pertinencia, equidad, eficacia y eficiencia. De esta manera, el programa @ prende 2.0 se centró en promover la tecnología como una herramienta esencial para alcanzar objetivos académicos (SEP, 2016).

En síntesis, se puede afirmar que han sido diversos los programas tecnológicos implementados por el Gobierno de México con el fin de reducir la brecha digital; sin embargo, los informes publicados sobre esas iniciativas coinciden en que existe una necesidad de capacitación pedagógica para el uso de las TIC (Glasserman y Manzano, 2016). Por tal motivo, surge la necesidad de identificar el nivel de dominio de las TIC de los niños de educación básica con el fin de proponer recomendaciones que permitan el desarrollo de sus competencias digitales.

\section{Educación y tecnología}

Actualmente, la sociedad se enfrenta a cambios acelerados y transformaciones profundas que repercuten en los procesos educativos. La integración de las TIC y su impacto en el ámbito social, laboral y académico imponen retos en la concepción de los procesos educativos (SEP, 2006). Se ha demostrado que la utilización de la tecnología impacta en la mejora de los procesos de enseñanza y aprendizaje, ya que permite construir entornos educativos virtuales que favorecen la innovación educativa (Salinas, 2008).

A nivel de educación básica, se han realizado diferentes estrategias con la finalidad de optimizar el aprendizaje de los estudiantes e involucrar a los profesores en el empleo de nuevas modalidades de enseñanza. Una de estas estrategias se sustenta en el aprovechamiento de las TIC dentro del salón de clases para alfabetizar digitalmente a los estudiantes y a los docentes de este nivel educativo (Díaz, Rodríguez, Sánchez, Rivera y Ramírez, 2015). Considerando que las nuevas generaciones de estudiantes son nativos digitales, se genera un gran desafío para los profesores, quienes deben familiarizar a los alumnos con estos recursos 


\section{Revista Iberoamericana \\ de las Ciencias Sociales y \\ Humanísticas}

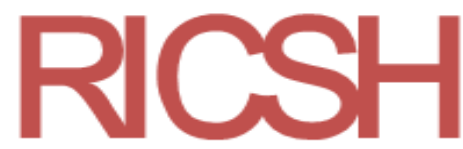

ISSN: 2395 - 7972

que representan un complemento esencial para la formación (Marchesi, Tedesco y Coll, 2010).

\section{Las TIC en la educación básica}

Las TIC son el resultado de una revolución digital que cada vez ocupa un lugar más protagónico en las aulas de clase. Por eso, cada vez más países se suman a la tarea de promover la alfabetización digital a través de diferentes programas gubernamentales. La incorporación de las TIC en los procesos educativos implica considerarlas tanto en la definición del currículo como en el diseño, así como en la implementación de estrategias pedagógicas y recursos didácticos que apoyen el desarrollo de nuevos aprendizajes, competencias y relaciones con el conocimiento (Santiago, Caballero, Gómez y Domínguez, 2013).

En varios países de Latinoamérica, así como en México se han impulsado estos planes de alfabetización digital a edad temprana. Los objetivos han sido el adecuado funcionamiento de los recursos informáticos digitales disponibles (tanto de hardware como de software), la conectividad y el acceso a Internet, las estrategias pedagógicas (que derivan en la promoción de un tipo de interacción entre los usuarios y las TIC), las habilidades digitales de profesores y estudiantes, así como la motivación hacia el uso adecuado de la tecnología y el tiempo disponible en cada clase para introducir este tipo de recursos (Santiago et al., 2013).

Hoy en día, en México la gran mayoría de las escuelas públicas de educación básica cuentan con nuevos recursos y herramientas para ampliar y fortalecer el aprendizaje de los niños y adolescentes, ya que — como se ha descrito anteriormente- este país ha establecido la incorporación de las TIC en los procesos de enseñanza y aprendizaje. Por ejemplo, estudios realizados en el municipio de Mérida (Yucatán) respecto a la competencia digital destacan que $86 \%$ de los estudiantes utilizan Internet como apoyo para la realización de diversas actividades académicas.

Sin embargo, también se ha indicado que no se aprovechan las ventajas que pueden ofrecer las tecnologías de la información y los medios de comunicación para crear escenarios más interesantes y flexibles que puedan ayudar al desarrollo de competencias digitales (SEP, 2009). Al respecto, Domínguez, Cisneros y Quiñonez (2019) —en su investigación llevada a cabo en una comunidad maya de Yucatán - señalan que si bien el Internet aporta diversos beneficios educativos, los niños y los jóvenes de las comunidades de habla maya tienen escasa información y preparación en cuanto al empleo de esas herramientas. 


\section{Revista Iberoamericana \\ de las Ciencias Sociales y \\ Humanísticas}

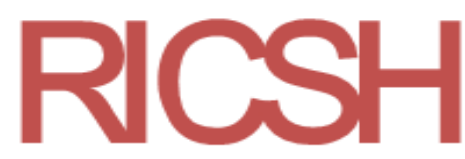

ISSN: 2395 - 7972

Aun así, también se ha demostrado que el uso de los dispositivos móviles en el municipio de Mérida (Yucatán) ha empezado a ser más habitual, de ahí la importancia de contar con instrumentos validados y confiables para recabar información veraz y precisa que permita, posteriormente, diseñar y aplicar intervenciones que ayuden al desarrollo de la competencia digital de los estudiantes del nivel básico (Bayona, Zapata, Quiñonez y Canto, 2017; Zapata, Quiñonez y Canto, 2017).

\section{Competencia digital}

La aparición del Internet y de las nuevas tecnologías han generado una revolución en la manera en que se divulga la información, lo que ha servido de base para acuñar el término sociedad del conocimiento (Flores y Roing, 2016). En este contexto, cada vez es más necesario el desarrollo de competencias digitales, las cuales son definidas por la Unesco (21 de marzo de 2018) como un "espectro de competencias que facilitan el uso de los dispositivos digitales, las aplicaciones de la comunicación y las redes para acceder a la información y llevar a cabo una mejor gestión de éstas" (párr.3).

Ahora bien, los diversos usos que se les puede dar a las TIC dentro del sistema educativo también han generado nuevos desafíos que no pueden ser soslayados (Pérez, 2010). Esto significa que la formación tecnológica debe trascender la simple capacitación tecnológica para profundizar en el entendimiento de la importancia que tienen las TIC como mediática para el logro de enseñanza y aprendizaje; a esto se le conoce como alfabetización digital.

En tal sentido, Gutiérrez (2012) explica que el papel del profesorado -debido a la abundancia de contenido disponible - debe cambiar de ser un proveedor de información a ser un facilitador de aprendizaje. Además, el proceso de actualización ahora debe de ser continúo debido a la rapidez con que la información se vuelve obsoleta. El profesor, por tanto, tiene que capacitarse en aprender a aprender como parte de su formación profesional a lo largo de toda la vida y debe ser consciente del nuevo perfil de los estudiantes actuales (conocidos como nativos digitales), cuyas características se pueden resumir de esta forma: reciben información de un modo muy rápido, realizan procesos en paralelo (es decir, pueden cumplir con múltiples tareas al mismo tiempo), prefieren gráficos en lugar de textos escritos, anteponen los procesos aleatorios (propios de la hipertextualidad), funcionan mejor en red y prefieren los juegos en lugar del trabajo "serio" (Prensky, 2001). 


\section{Revista Iberoamericana \\ de las Ciencias Sociales y \\ Humanísticas}

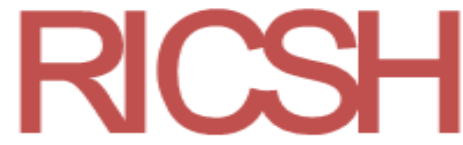

ISSN: 2395 - 7972

Por ese motivo, los estudiantes de esta época necesitan de una formación que se encuentre inmersa en el mundo tecnológico y que les proponga nuevas maneras de aprender y de acercarse a la información, lo que obliga a los docentes a conseguir una actualización en cuanto al uso de las TIC.

\section{Método}

La presente investigación se sustentó en un enfoque cuantitativo y descriptivo, pues se procuró determinar cómo se manifiesta cierto fenómeno en un contexto determinado. Igualmente, este se puede considerar un estudio transversal, puesto que la medición y recolección de los datos se realizó en un solo momento en el tiempo (Hernández, Fernández y Baptista, 2013). Para ello, se empleó una encuesta que permitió recabar información en torno a la opinión y las actitudes de las personas (Isaac y Michael, 1995). Según González, Calleja, López, Padrino y Puebla (2009), los estudios tipo encuesta son útiles para describir y predecir un fenómeno educativo y para obtener un primer contacto con la realidad (figura 1).

Figura 1. Diseño del estudio tipo encuesta

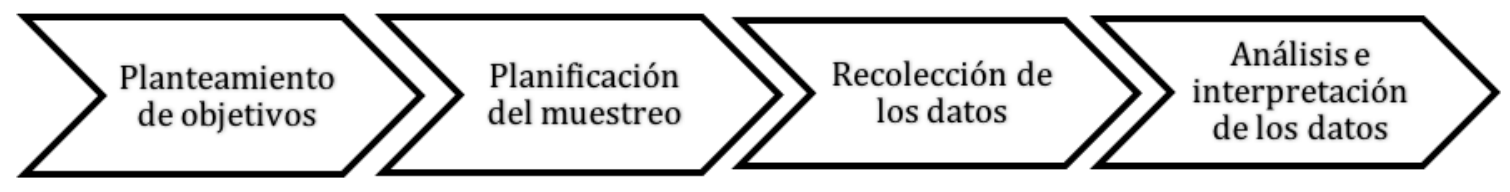

Fuente: Arnau (1995)

Siguiendo las fases del estudio tipo encuesta propuestas por Arnau (1995), en la primera etapa se planteó el objetivo del estudio, es decir, describir la competencia digital de los niños de educación básica pertenecientes al municipio de Mérida (Yucatán), específicamente en lo referente al manejo de información, comunicación y aprendizaje colaborativo, ciudadanía digital y creatividad e innovación.

En la segunda etapa — para la selección de los participantes-, se realizó un muestreo no probabilístico por conveniencia (Casal y Mateu, 2003), para lo que se tomaron en cuenta los siguientes criterios: ser menor de edad, ser estudiante de sexto grado de primaria y haber participado en el programa @ prende.mx. En definitiva, la muestra quedó constituida por 160 niños.

En la tercera etapa (recolección de datos) se elaboró el instrumento, el cual se ideó tomando en cuenta los estándares de habilidades digitales planteados por la coordinación general del programa @ prende.mx (Villegas, Mortis, García y Del Hierro, 2017). En el primer apartado del instrumento se solicitó a los participantes información general. En el segundo se les preguntó sobre el número de horas que duraban conectados a internet y las 


\section{Revista Iberoamericana \\ de las Ciencias Sociales y \\ Humanísticas}

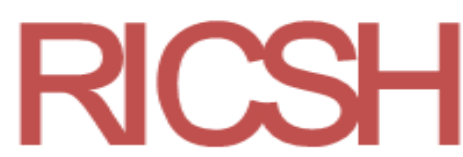

ISSN: 2395 - 7972

aplicaciones que tenían instaladas en sus dispositivos móviles. El tercer y último apartado quedó conformado por 23 reactivos, los cuales fueron agrupados en cuatro dimensiones enfocadas en el uso de las TIC:

1. Manejo de la información: Se refiere al uso de herramientas digitales para recabar, seleccionar, analizar, evaluar y utilizar información, así como para procesar datos y comunicar resultados.

2. Comunicación y aprendizaje colaborativo: Esta dimensión se enfoca en la utilización de medios y entornos digitales para comunicar ideas e información a una audiencia múltiple, así como para interactuar con otros y trabajar de forma colaborativa.

3. Ciudadanía digital: Precisa la comprensión de asuntos humanos, culturales y sociales relacionados con el uso de las TIC y la aplicación de conductas éticas, legales, seguras y responsables en su uso.

4. Creatividad e innovación: Se vincula con el pensamiento creativo, el desarrollo de productos y los procesos innovadores utilizando las TIC y la construcción de conocimiento. 


\section{Revista Iberoamericana \\ de las Ciencias Sociales y \\ Humanísticas}

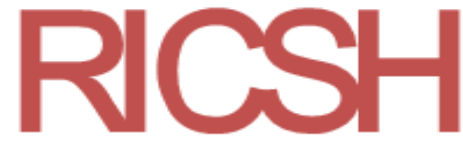

ISSN: $2395-7972$

Figura 2. Apartado del instrumento enfocado en el Modo en que los estudiantes hacen uso de

las TIC

\begin{tabular}{|c|c|c|c|c|}
\hline \multicolumn{5}{|c|}{ El modo que los estudiantes hacen uso de las TIC } \\
\hline \multicolumn{2}{|c|}{ 1. Nunca $(\mathrm{N})$} & 2. Rara vez (RV) & 3. Frecuentemente $(\mathrm{F})$ & 4. Siempre (S) \\
\hline \multicolumn{5}{|c|}{ Manejo de la información } \\
\hline 1 & \multicolumn{4}{|c|}{ Utilizo Internet para hacer mi tarea } \\
\hline 2 & \multicolumn{4}{|c|}{ Busco información relacionada con temas o actividades vistas en clase } \\
\hline 3 & \multicolumn{4}{|c|}{ Busco temas de mi interés en Internet } \\
\hline 4 & \multicolumn{4}{|c|}{ Utilizo materiales digitales precargados en mi tableta para hacer mis tareas escolares } \\
\hline 5 & \multicolumn{4}{|c|}{$\begin{array}{l}\text { Utilizo materiales digitales interactivos como juegos, simuladores, etc. para mi } \\
\text { entretenimiento }\end{array}$} \\
\hline 6 & \multicolumn{4}{|c|}{ Comparto lo que encuentro en internet con compañeros, maestros o familiares } \\
\hline 7 & \multicolumn{4}{|c|}{ Guardo archivos, fotos, etc. en OneDrive, Dropbox, Google Drive o iCloud } \\
\hline \multicolumn{5}{|c|}{ Comunicación y aprendizaje colaborativo } \\
\hline 8 & \multicolumn{4}{|c|}{ Público y comparto ideas, opiniones o imágenes de manera respetuosa en redes sociales } \\
\hline 9 & \multicolumn{4}{|c|}{$\begin{array}{l}\text { Algún adulto (padres o maestros) está pendiente de la información que publico y comparto } \\
\text { en las redes }\end{array}$} \\
\hline 10 & \multicolumn{4}{|c|}{ Hago trabajos en equipo usando la tableta } \\
\hline 11 & \multicolumn{4}{|c|}{ Hago visitas virtuales a museos, ciudades o países para conocer de arte y cultura } \\
\hline 12 & \multicolumn{4}{|c|}{$\begin{array}{l}\text { Utilizo redes sociales (WhatsApp, Facebook, Instagram etc.) para comunicarme o } \\
\text { intercambiar información sobre temas de la escuela }\end{array}$} \\
\hline 13 & \multicolumn{4}{|c|}{$\begin{array}{l}\text { Utilizo redes sociales (WhatsApp, Facebook, Instagram etc.) para comunicarme o } \\
\text { intercambiar información con amigos o familiares }\end{array}$} \\
\hline \multicolumn{5}{|c|}{ Ciudadanía Digital } \\
\hline 14 & \multicolumn{4}{|c|}{$\begin{array}{l}\text { Utilizo los dispositivos móviles (celular, tableta, laptop) de manera limitada y bajo } \\
\text { supervisión }\end{array}$} \\
\hline 15 & \multicolumn{4}{|c|}{$\begin{array}{l}\text { He visto en Internet sitios, videos e imágenes que expresen violencia y utilicen un lenguaje } \\
\text { ofensivo }\end{array}$} \\
\hline 16 & \multicolumn{4}{|c|}{$\begin{array}{l}\text { Mantengo una interacción respetuosa y cordial promoviendo una sana convivencia en las } \\
\text { redes sociales }\end{array}$} \\
\hline 17 & \multicolumn{4}{|c|}{ Hago bromas, burlas o juegos a mis compañeros o amigos a través de las redes sociales } \\
\hline 18 & \multicolumn{4}{|c|}{ Me han burlado, insultado o rechazado a través de las redes sociales } \\
\hline 19 & \multicolumn{4}{|c|}{ Recibo información sobre el uso seguro y responsable de los dispositivos móviles } \\
\hline \multicolumn{5}{|c|}{ Creatividad e innovación } \\
\hline 20 & \multicolumn{4}{|c|}{ Expreso mis ideas mediante la creación de audio, video, imágenes, texto } \\
\hline 21 & \multicolumn{4}{|c|}{ Creo mapas conceptuales en la tableta para organizar información e ideas } \\
\hline 22 & \multicolumn{4}{|c|}{ Utilizo los software o contenidos precargados en la tableta } \\
\hline 23 & \multicolumn{4}{|c|}{ Selecciono y guardo mis trabajos como muestra de mis avances digitales } \\
\hline
\end{tabular}

Fuente: Elaboración propia

Como se observa en la figura anterior, la escala del instrumento fue tipo Likert, con las siguientes opciones de respuesta: nunca, rara vez, frecuentemente y siempre; este tipo de escalas constituye uno de los formatos más utilizados cuando se desea preguntar varias cuestiones que comparten las mismas opciones de respuesta (Cea D’Ancona, 2001).

Como parte del análisis psicométrico efectuado al instrumento para determinar su confiabilidad y validez, se realizó la prueba de discriminación de reactivos comparando las puntuaciones en cada uno de estos. Con base en los datos obtenidos, se determinó que a los participantes cuyas puntuaciones estuvieran por arriba del cuartil 75 se les consideraría competentes digitales; en cambio, si obtenían puntuaciones ubicadas por debajo del cuartil 25, se les consideraría deficientes en cuanto a competencia digital. Este proceso estadístico se realizó a través de una prueba $t$ para muestras independientes (tabla 1). 


\section{Revista Iberoamericana \\ de las Ciencias Sociales y \\ Humanísticas}

Tabla 1. Prueba de discriminación de reactivos

\begin{tabular}{|c|c|c|}
\hline Reactivos & $t$ & $p$ \\
\hline Utilizo Internet para hacer mi tarea. & -4.642 & 0.000 \\
\hline Busco información relacionada con temas o actividades vistas en clase. & -2.203 & 0.030 \\
\hline Busco temas de mi interés en Internet. & -4.320 & 0.000 \\
\hline $\begin{array}{l}\text { Utilizo materiales digitales precargados en mi tableta para hacer mis tareas } \\
\text { escolares. }\end{array}$ & -4.392 & 0.000 \\
\hline $\begin{array}{l}\text { Utilizo materiales digitales interactivos como juegos, simuladores, etc., para } \\
\text { mi entretenimiento. }\end{array}$ & -4.303 & 0.000 \\
\hline $\begin{array}{l}\text { Comparto lo que encuentro en Internet con compañeros, maestros o } \\
\text { familiares. }\end{array}$ & -3.032 & 0.003 \\
\hline Guardo archivos, fotos, etc., en OneDrive, Dropbox, Google Drive o iCloud. & -6.863 & 0.000 \\
\hline $\begin{array}{l}\text { Público y comparto ideas, opiniones o imágenes de manera respetuosa en } \\
\text { redes sociales. }\end{array}$ & -4.410 & 0.000 \\
\hline $\begin{array}{l}\text { Algún adulto (padres o maestros) está pendiente de la información que } \\
\text { publico y comparto en las redes. }\end{array}$ & -6.833 & 0.000 \\
\hline Hago trabajos en equipo usando la tableta. & -8.295 & 0.000 \\
\hline $\begin{array}{l}\text { Utilizo redes sociales (WhatsApp, Facebook, Instagram, etc.) para } \\
\text { comunicarme o intercambiar información sobre temas de la escuela. }\end{array}$ & -3.242 & 0.002 \\
\hline $\begin{array}{l}\text { Utilizo redes sociales (WhatsApp, Facebook, Instagram, etc.) para } \\
\text { comunicarme o intercambiar información con amigos o familiares. }\end{array}$ & -6.774 & 0.000 \\
\hline $\begin{array}{l}\text { Utilizo los dispositivos móviles (celular, tableta, laptop) de manera limitada y } \\
\text { bajo supervisión. }\end{array}$ & -5.210 & 0.000 \\
\hline $\begin{array}{l}\text { He visto en Internet sitios, videos e imágenes que expresen violencia y } \\
\text { utilicen un lenguaje ofensivo. }\end{array}$ & -2.710 & 0.008 \\
\hline $\begin{array}{l}\text { Mantengo una interacción respetuosa y cordial promoviendo una sana } \\
\text { convivencia en las redes sociales. }\end{array}$ & -4.538 & 0.000 \\
\hline $\begin{array}{l}\text { Hago bromas, burlas o juegos a mis compañeros o amigos a través de las } \\
\text { redes sociales. }\end{array}$ & -5.864 & 0.000 \\
\hline Me han burlado, insultado o rechazado a través de las redes sociales. & -3.853 & 0.000 \\
\hline $\begin{array}{l}\text { Recibo información sobre el uso seguro y responsable de los dispositivos } \\
\text { móviles. }\end{array}$ & -10.881 & 0.000 \\
\hline Expreso mis ideas mediante la creación de audio, video, imágenes, texto. & -8.741 & 0.000 \\
\hline Creo mapas conceptuales en la tableta para organizar información e ideas. & -5.529 & 0.000 \\
\hline Utilizo los softwares o contenidos precargados en la tableta. & -10.881 & 0.000 \\
\hline Selecciono y guardo mis trabajos como muestra de mis avances digitales. & -8.741 & 0.000 \\
\hline $\begin{array}{l}\text { Utilizo programas gratis por Internet para realiza alguna actividad de gusto } \\
\text { personal. }\end{array}$ & -5.529 & 0.000 \\
\hline
\end{tabular}

Fuente: Elaboración propia

Del análisis de los resultados obtenidos en la tabla 1 se determinó que los reactivos sí discriminan, ya que el valor de significancia $(p)$ fue menor a 0.05. Asimismo, se corrió la prueba estadística denomina alfa de Cronbach y se obtuvo un valor de 0.808 , resultado que demostró la confiabilidad del cuestionario. Al respecto, George y Mallery (2003) señalan que un coeficiente de alfa igual o mayor a 0.8 indica que el instrumento es confiable.

La recolección de los datos se realizó en las instalaciones asignadas para el proyecto de investigación y fue por medio del cuestionario que se administró en un solo momento. El instrumento se contestó en formato de papel y lápiz. El proceso contó con la colaboración de los niños de sexto grado, los instructores y el responsable de la investigación. Los instructores 


\section{Revista Iberoamericana \\ de las Ciencias Sociales y \\ Humanísticas}

ISSN: $2395-7972$

fueron los encargados de proporcionar los cuestionarios y dar las instrucciones para contestarlos. El responsable de la investigación comunicó cuál era el objetivo del cuestionario y solicitó a los encuestados su total sinceridad para cada una de las respuestas; de igual manera, siempre estuvo pendiente de las dudas o comentarios que pudieran surgir durante la administración del instrumento.

En la cuarta fase se codificaron y analizaron los datos obtenidos por medio del programa Statistical Package for the Social Sciences (SPSS). Como resultado, se realizaron pruebas de estadística descriptiva en las cuales se consiguieron porcentajes y frecuencias de los datos. Este análisis permitió determinar el nivel de competencia digital respecto al manejo de la información, comunicación y aprendizaje colaborativo, ciudadanía digital y creatividad e innovación. Asimismo, se realizó la prueba $t$ de Student para muestras independientes, la cual permitió detectar si había diferencia entre niños y niñas respecto a la frecuencia del uso de las TIC y las horas que utilizaban el Internet a diario. También se realizaron gráficas de barras con algunos reactivos del instrumento con el objetivo de consolidar los resultados respecto al nivel de competencia digital en los niños y niñas de educación básica.

\section{Resultados}

En esta primera parte de los resultados se indica que el instrumento cuantitativo fue contestado por 160 estudiantes de educación básica: 47 \% niños y 53 \% niñas. Al analizar los resultados obtenidos, se pudo evidenciar que $96 \%$ de los encuestados tienen un teléfono celular inteligente. Otro dato importante es que $59 \%$ de los estudiantes usan sus dispositivos móviles de 6 a 7 días a la semana, mientras que solo 12 \% lo usan 1 día a la semana. También se pudo evidenciar que $39 \%$ de los estudiantes navegan más de 5 horas en Internet, mientras que $13 \%$ lo hacen 1 hora al día (figura 3 ). 


\section{Revista Iberoamericana \\ de las Ciencias Sociales y \\ Humanísticas}

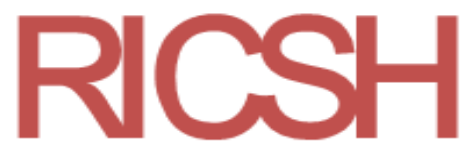

ISSN: 2395 - 7972

Figura 3. Porcentaje de uso del Internet por día

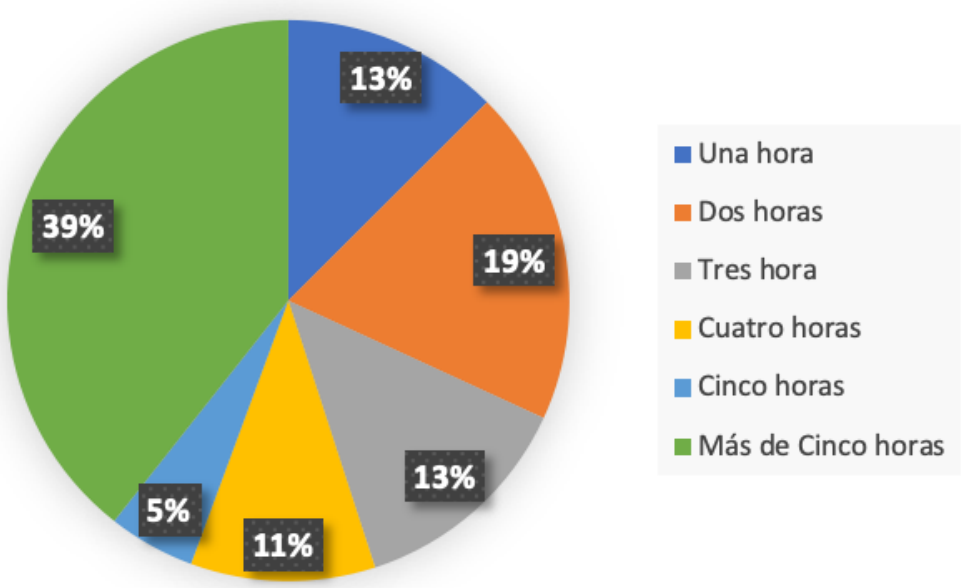

Fuente: Elaboración propia

Por otra parte, se pudo conocer que 144 de los encuestados utilizan en sus dispositivos móviles aplicaciones de videojuegos, y solo 48 usan aplicaciones educativas (figura 4).

Figura 4. Distribución del uso de las aplicaciones

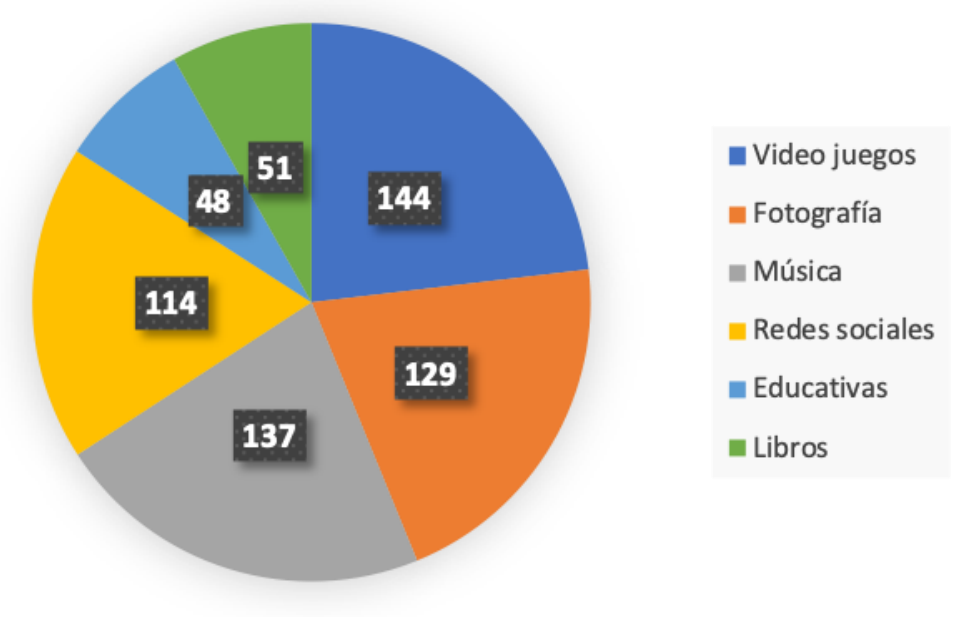

Fuente: Elaboración propia

Ahora bien, en esta segunda parte de la investigación se presentan cifras para analizar el nivel de dominio en el uso de las TIC de los estudiantes consultados. Para este proceso, la categorización se determinó con base en lo mencionado por Quiñonez, Zapata y Canto (2018) en torno al porcentaje del dominio del uso de las TIC, es decir, si menos de $70 \%$ de la población se ubica en el nivel alto de la escala (frecuentemente y siempre), el rubro evaluado sería considerado para futuras intervenciones (tabla 2). 


\section{Revista Iberoamericana \\ de las Ciencias Sociales y \\ Humanísticas}

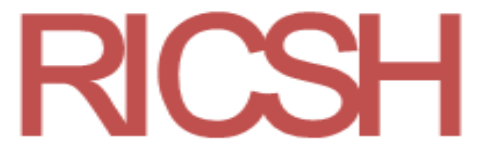

ISSN: $2395-7972$

Tabla 2. Nivel de competencia digital de los niños de educación básica

\begin{tabular}{|l|c|}
\hline \multicolumn{1}{|c|}{ Aspecto evaluado } & $\begin{array}{c}\text { Alto } \\
\text { \% }\end{array}$ \\
\hline Utilizo Internet para hacer mi tarea. & 48.1 \\
\hline Busco información relacionada con temas o actividades vistas en clase. & 82.5 \\
\hline Busco temas de mi interés en Internet. & 43.8 \\
\hline $\begin{array}{l}\text { Utilizo materiales digitales precargados en mi tableta para hacer mis tareas } \\
\text { escolares. }\end{array}$ & 32.5 \\
\hline $\begin{array}{l}\text { Utilizo materiales digitales interactivos como juegos, simuladores, etc., para mi } \\
\text { entretenimiento. }\end{array}$ & 48.8 \\
\hline Comparto lo que encuentro en internet con compañeros, maestros o familiares. & 59.3 \\
\hline Guardo archivos, fotos, etc., en OneDrive, Dropbox, Google Drive o iCloud. & 53.1 \\
\hline $\begin{array}{l}\text { Público y comparto ideas, opiniones o imágenes de manera respetuosa en redes } \\
\text { sociales. }\end{array}$ & 38.1 \\
\hline $\begin{array}{l}\text { Algún adulto (padres o maestros) está pendiente de la información que publico y } \\
\text { comparto en las redes. }\end{array}$ & 46.8 \\
\hline Hago trabajos en equipo usando la tableta. & 70.0 \\
\hline $\begin{array}{l}\text { Utilizo redes sociales (WhatsApp, Facebook, Instagram, etc.) para comunicarme o } \\
\text { intercambiar información sobre temas de la escuela. }\end{array}$ & 41.3 \\
\hline $\begin{array}{l}\text { Utilizo redes sociales (WhatsApp, Facebook, Instagram, etc.) para comunicarme o } \\
\text { intercambiar información con amigos o familiares. }\end{array}$ & 61.2 \\
\hline $\begin{array}{l}\text { Mantengo una interacción respetuosa y cordial promoviendo una sana } \\
\text { convivencia en las redes sociales. }\end{array}$ & 68.7 \\
\hline Expreso mis ideas mediante la creación de audio, video, imágenes, texto. & 56.2 \\
\hline Creo mapas conceptuales en la tableta para organizar información e ideas. & 71.2 \\
\hline Utilizo los softwares o contenidos precargados en la tableta. & 56.2 \\
\hline Selecciono y guardo mis trabajos como muestra de mis avances digitales. & 55.0 \\
\hline $\begin{array}{l}\text { Utilizo programas gratis por Internet para realizar alguna actividad de gusto } \\
\text { personal. }\end{array}$ & 71.2 \\
\hline
\end{tabular}

Fuente: Elaboración propia

Con base en los resultados de la tabla 2 , se puede decir que $78 \%$ de los niños de educación básica que participaron en este trabajo están por debajo de $70 \%$, lo que significa que poseen un nivel limitado respecto al dominio en el uso de las TIC. En consecuencia, es necesario diseñar intervenciones que desarrollen en ellos competencias digitales, para lo cual se pueden tener en cuenta aspectos como los siguientes: uso del Internet para actividades académicas, utilización responsable de las redes, desarrollo de recursos para expresar ideas por medio de audio, video, imágenes, etc.

Los rubros que estuvieron igual o por encima de $70 \%-y$ que no se consideran para una posible intervención - fueron los relacionados con el trabajo colaborativo mediado por tecnología, búsquedas de información relacionadas con tareas escolares, uso de aplicaciones gratuitas para realizar actividades de gusto personal y organización de información a través de 


\section{Revista Iberoamericana \\ de las Ciencias Sociales y \\ Humanísticas}

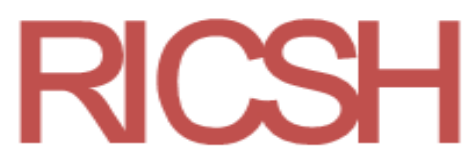

ISSN: 2395 - 7972

mapas conceptuales en formato digital. Esto indica que los estudiantes en su mayoría realizan frecuentemente o siempre dichas acciones mediante las TIC.

A continuación, se presenta la tercera parte del análisis de los resultados. En esta se comparan por género la frecuencia de utilización de las TIC a la semana y las horas completas que utilizan el Internet a diario. Como se puede observar en la tabla 3, no se registró diferencia significativa entre las medias de los dos grupos, pues tanto los niños como las niñas puntúan de manera similar en relación con la frecuencia con la que utilizan las TIC a la semana (valor de $p>0.05$ ). Esto significa que ambos usan las TIC con la misma frecuencia.

Tabla 3. Comparación por género de la frecuencia de uso de las TIC

\begin{tabular}{|c|c|c|}
\hline $\boldsymbol{t}$ & $\boldsymbol{g} \boldsymbol{P}$ & $\boldsymbol{P}$ \\
\hline-0.381 & 42 & 0.705 \\
\hline
\end{tabular}

Fuente: Elaboración propia

En la tabla 4 se puede observar que no se encontró diferencia significativa entre las medias de los dos grupos, ya que tanto los niños como las niñas puntúan de manera similar respecto a las horas completas que utilizan el Internet a diario (valor de $p>0.05$ ). Esto significa que ambos usan el Internet los mismos periodos.

Tabla 4. Comparación por género de las horas completas que utilizan el Internet a diario

\begin{tabular}{|c|c|c|}
\hline $\boldsymbol{t}$ & $\boldsymbol{g} \boldsymbol{P}$ & $\boldsymbol{P}$ \\
\hline-0.134 & 49 & 0.894 \\
\hline
\end{tabular}

Fuente: Elaboración propia

Por último, se presenta la cuarta parte del análisis estadístico para consolidar la información antes presentada y para proponer estrategias y futuras intervenciones que permitan el desarrollo de competencias digitales en los niños y niñas de educación básica. A continuación, se describen los resultados obtenidos en algunos reactivos que integraron la dimensión ciudadanía digital. El primer reactivo responde a la afirmación Utilizo los dispositivos móviles (celular, tableta, computadora portátil) de manera limitada y bajo supervisión (figura 5). 


\section{Revista Iberoamericana \\ de las Ciencias Sociales y \\ Humanísticas}

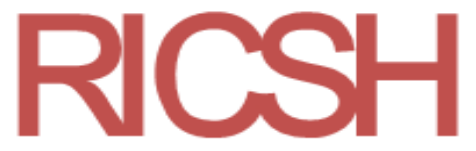

ISSN: 2395 - 7972

Figura 5. Porcentaje de respuestas al reactivo Utilizo los dispositivos móviles (celular, tableta, computadora portátil) de manera limitada y bajo supervisión

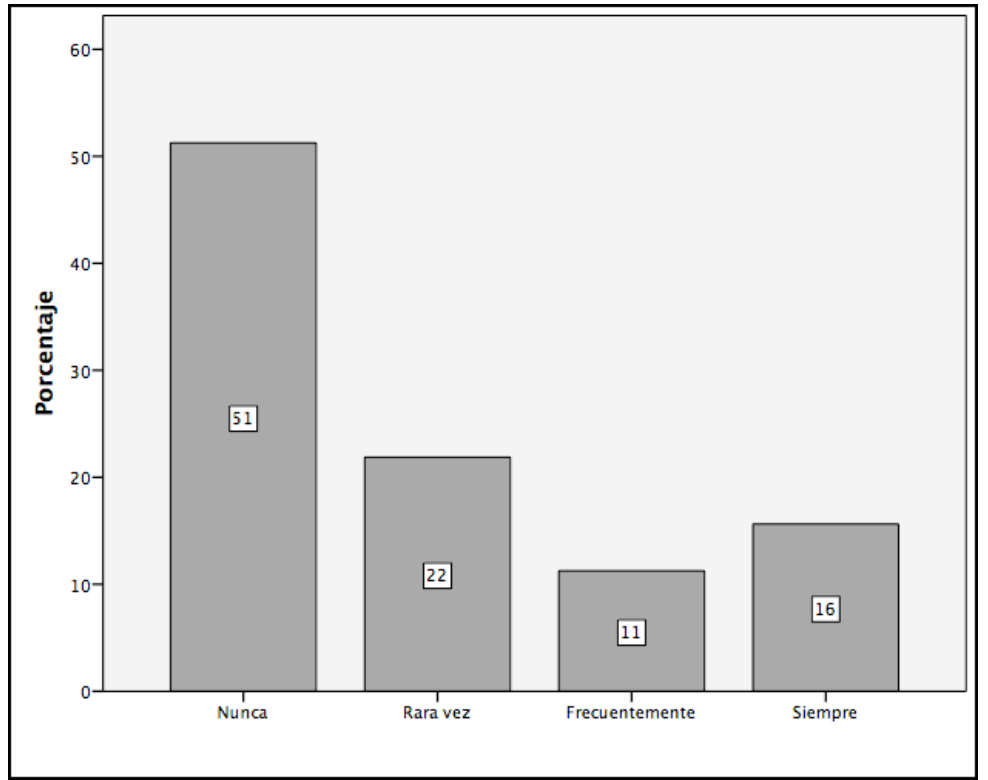

Fuente: Elaboración propia

Con base en las respuestas proporcionadas en la figura anterior, se puede afirmar que $73 \%$ de los estudiantes nunca o rara vez utilizan los dispositivos móviles de manera limitada y bajo supervisión. En el segundo reactivo se solicitó a los estudiantes que respondieran con base en la afirmación He visto en Internet sitios, videos e imágenes que expresen violencia y utilicen un lenguaje ofensivo (figura 6).

Figura 6. Porcentaje de respuestas al reactivo He visto en Internet sitios, videos e imágenes que expresen violencia y utilicen un lenguaje ofensivo

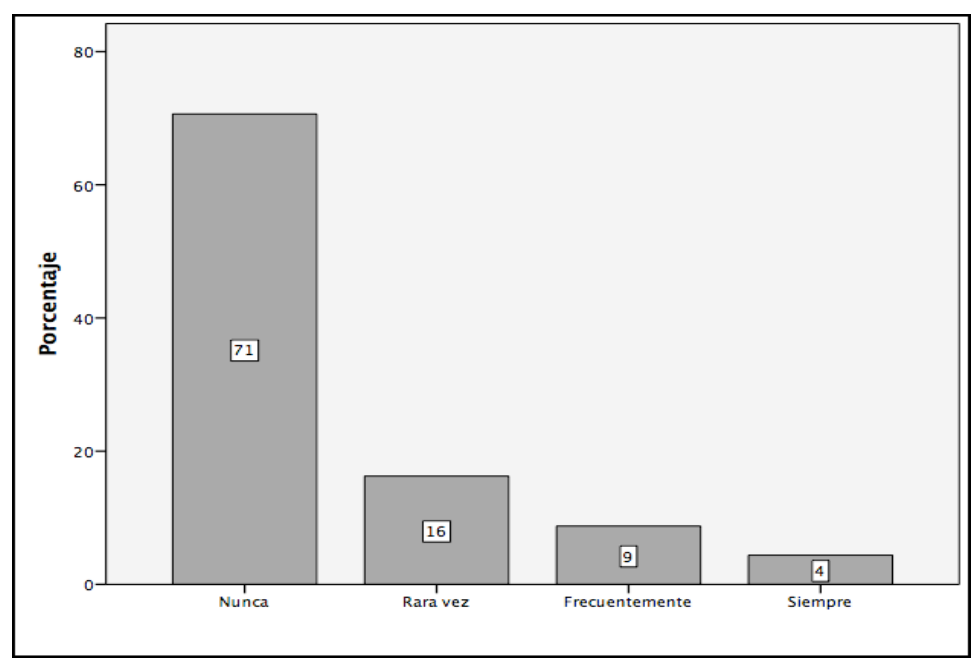

Fuente: Elaboración propia 


\section{Revista Iberoamericana \\ de las Ciencias Sociales y \\ Humanísticas}

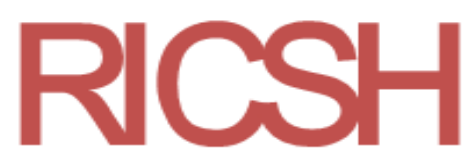

ISSN: 2395 - 7972

Tomando en cuenta las respuestas obtenidas en la figura 6, se puede afirmar que $87 \%$ de los estudiantes nunca o rara vez han visto imágenes o videos con lenguajes ofensivos. En el tercer reactivo se solicitó a los estudiantes que respondieran con base en la afirmación Hago bromas, burlas o juegos a mis compañeros o amigos a través de las redes sociales (figura 7).

Figura 7. Porcentaje de respuestas al reactivo Hago bromas, burlas o juegos a mis compañeros o amigos a través de las redes sociales

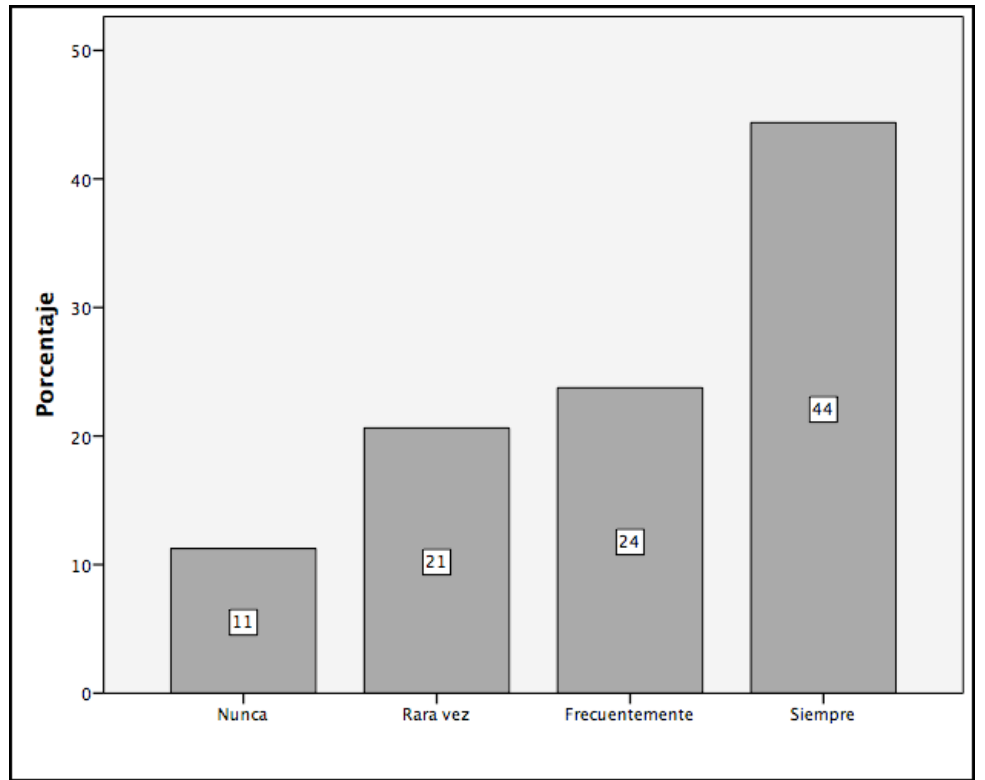

Fuente: elaboración propia

Como se puede observar en la figura 7, $68 \%$ de los estudiantes frecuentemente o siempre han bromeado o burlado a sus compañeros o amigos a través de las redes sociales. En el cuarto reactivo se solicitó a los estudiantes que respondieran con base en la afirmación $\mathrm{Me}$ han burlado, insultado o rechazado a través de las redes sociales (figura 8). 
Figura 8. Porcentaje de respuestas al reactivo Me han burlado, insultado o rechazado a través de las redes sociales

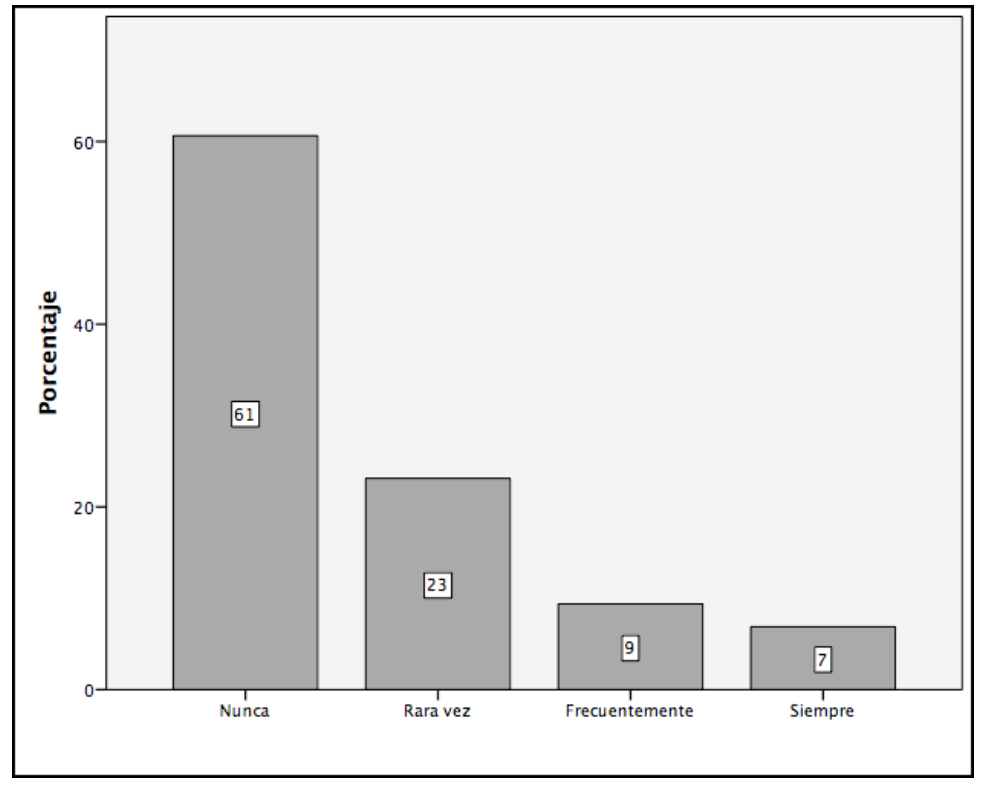

Fuente: Elaboración propia

Con base en los resultados de la figura 8 , se puede afirmar que $84 \%$ de los estudiantes nunca o rara vez han sido burlados, insultados o rechazados a través de las redes sociales. En el último reactivo de la dimensión antes mencionada se solicitó a los estudiantes que respondieran con base en la afirmación Recibo información sobre el uso seguro y responsable de los dispositivos móviles (figura 9). 


\section{Revista Iberoamericana \\ de las Ciencias Sociales y \\ Humanísticas}

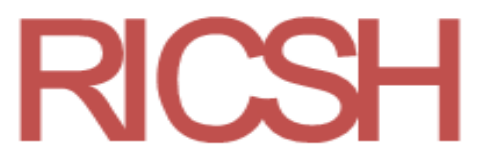

ISSN: 2395 - 7972

Figura 9. Porcentaje de respuestas al reactivo Recibo información sobre el uso seguro y responsable de los dispositivos móviles

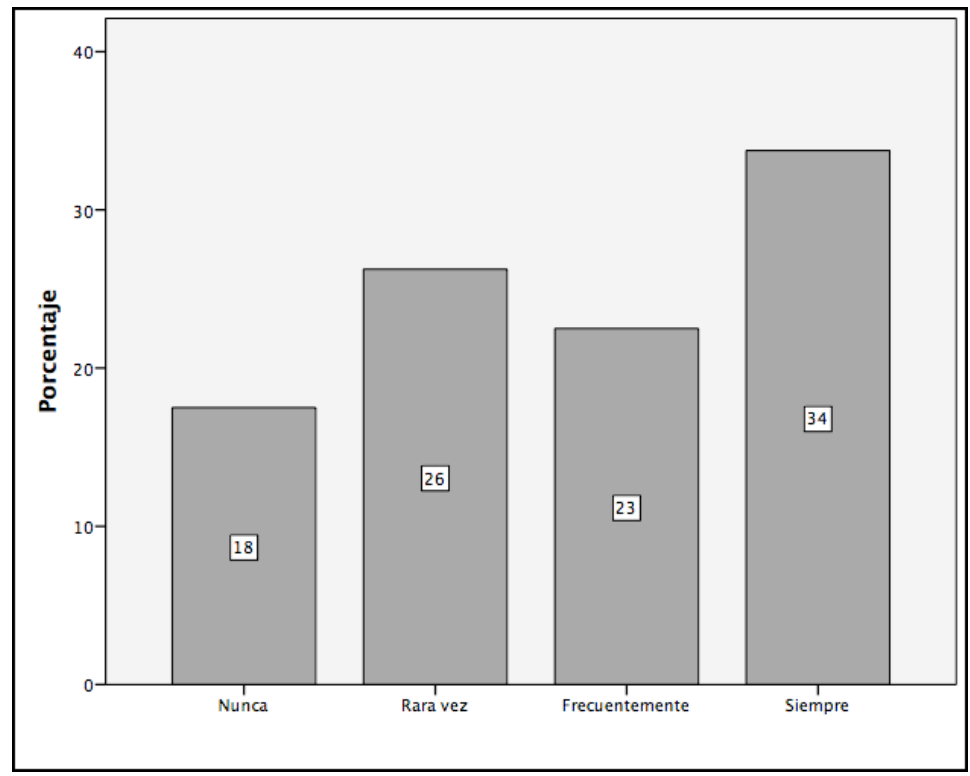

Fuente: Elaboración propia

Como se observa en la figura 9, 44\% de los estudiantes nunca o rara vez han recibido información respecto al uso seguro y responsable de los dispositivos móviles.

\section{Discusión}

Como se pudo evidenciar en los resultados, todos los niños que participaron en este estudio usan las TIC desde temprana edad, de ahí que sean considerados como nativos digitales (Presnky, 2001). De hecho, y de forma más concreta, se puede decir $90 \%$ de ellos emplean las aplicaciones para el entretenimiento (p. ej., videojuegos), mientras que solo $30 \%$ utilizan aplicaciones educativas, de ahí que se desperdicie el potencial de estas herramientas para estimular el aprendizaje. Al respecto, Marchesi et al. (2010) apuntan que los estudiantes deben de valorar el uso de las tecnologías como una mediática importante para la formación.

Asimismo, se pudo comprobar en el estudio que $78 \%$ de los participantes no tienen un dominio en torno al uso de las TIC, por lo que es necesario desarrollar en ellos competencias digitales para que puedan aprovechar el Internet en actividades académicas, así como para que usen de forma responsable las redes cuando deban usarlas para expresar sus ideas. Sobre este elemento, vale destacar la idea de Aviram (2002, citado por Marqués, 2012), quien subraya la importancia de la formación en el uso de las TIC desde los escenarios tecnócrata, reformista y holístico para que los estudiantes desde los niveles básicos valoren las tecnologías como mediática para consolidar su desarrollo académico. 


\section{Revista Iberoamericana \\ de las Ciencias Sociales y \\ Humanísticas}

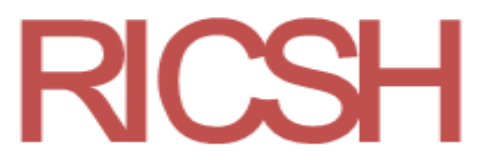

ISSN: $2395-7972$

Por otra parte, en el análisis realizado a la dimensión del cuestionario ciudadanía digital, se demostró que $73 \%$ de los estudiantes utilizan de manera ilimitada y sin supervisión de algún adulto sus dispositivos móviles. Asimismo, se detectó que $68 \%$ de los estudiantes frecuentemente o siempre hacen bromas o se burlan de sus compañeros o amigos a través de las redes sociales. Estas cifras sirven para profundizar en los riesgos que subyacen en el uso de las tecnologías y del Internet cuando no se brinda la supervisión adecuada. En tal sentido, Echeburúa y De Corral (2010) mencionan que el Internet y las redes sociales pueden servir para que los usuarios accedan a contenidos inapropiados o violentos, lo que puede incitar o desencadenar conductas éticamente reprochables.

Teniendo en cuenta lo analizado, se debe crear conciencia sobre el buen uso de las TIC en los niños y niñas de educación básica para que desarrollen competencias digitales que los ayuden en su formación académica. De ese modo se pueden prevenir situaciones habituales en la actualidad que socaban la autoestima de los alumnos, como sucede con los acosos en línea.

\section{Conclusiones}

Como se pudo observar en este trabajo, la SEP ha implementado a lo largo del tiempo diversos programas que promueven el uso de las TIC con el objetivo de desarrollar competencias digitales en los estudiantes de educación básica. Sin embargo, esas iniciativas no han tenido el éxito esperado, pues — como se demuestra en este trabajo- $78 \%$ de los niños del nivel básico consultados poseen un dominio limitado de las TIC y no suelen hacer uso responsable y ético de esas tecnologías.

Por eso, resulta esencial que se generen espacios de capacitación tanto para los estudiantes como para los profesores del nivel básico, pues se debe fomentar el uso responsable de las TIC, así como consolidar las estrategias de alfabetización digital para aprovechar las bondades que ofrece Internet en el cumplimiento de las asignaciones escolares.

Por otra parte, los resultados evidencian que no existen diferencias significativas en cuanto al sexo, la frecuencia de uso de las TIC y las horas al día que se conectan a la Web. Por lo anterior, se puede inferir que tanto los niños como las niñas tienen las mismas oportunidades para acceder y emplear estas tecnologías. Por ello, se sugiere a los profesores y a las autoridades de educación básica que fomenten el uso académico de las TIC dentro y fuera del aula. Para esto, lógicamente, se deben consolidar los procesos de capacitación del profesorado en cuanto al uso de los dispositivos móviles con fines académicos, así como alinear las actividades escolares con los objetivos del Programa Institucional de 


\section{Revista Iberoamericana \\ de las Ciencias Sociales y \\ Humanísticas}

ISSN: $2395-7972$

Alfabetización Digital (PIAD), pues en este se describen actividades para favorecer el aprendizaje y para fomentar el desarrollo de las habilidades del pensamiento. En síntesis, se debe tener en cuenta que el desarrollo de las competencias digitales y éticas depende en gran medida de las acciones que realicen los docentes y las autoridades educativas.

\section{Referencias}

Arnau, J. (1995). Metodologías cuantitativas en la investigación psicológica. Barcelona, España: Experimental.

Bayona, N., Zapata, A., Quiñonez, S. y Canto, P. (2017). Diseño y validación de un cuestionario para valorar el uso de dispositivos móviles en estudiantes de quinto año de primaria. En Mortís, S., Muñoz, J. y Zapata, A. (coords.), Reducción de brecha digital e inclusión educativa: experiencias en el norte, centro y sur de México (pp. 151-163). México: Editorial: Rosa María Porrúa.

Casal, J. y Mateu, E. (2003). Tipos de muestreo. Revista de Epidemiología y Medicina Preventiva, 1, 3-7.

Cea D'Ancona, M. (2001). Metodología cuantitativa. Estrategias y técnicas de investigación social. Madrid: Síntesis.

Díaz, D., Rodríguez, M., Sánchez, W., Rivera, N. y Ramírez, M. (2015). Competencias digitales en el marco del programa Mi Compu Mx: estudio piloto en Colima, Sonora y Tabasco. Memorias del Segundo Congreso Internacional de Innovación Educativa. Recuperado https://www.researchgate.net/publication/318982616_Competencias_digitales_en_el_ marco_del_programa_Mi_CompuMx_Estudio_piloto_en_Colima_Sonora_y_Tabasco

Domínguez, J., Cisneros, E. y Quiñonez, S. (2019). Vulnerabilidad ante el uso del Internet de niños y jóvenes de comunidades mayahablantes del sureste de México. Revista Iberoamericana para la Investigación y el Desarrollo Educativo, 10(19), 1-30.

Echeburúa, E. y De Corral, P. (2010). Adicción a las nuevas tecnologías y a las redes sociales en jóvenes: un nuevo reto. Adicciones, 22(2), 91-95. Recuperado de http://www.adicciones.es/index.php/adicciones/article/view/196/186

Flores, C. y Roing, R. (2016). Competencia digital docente: una cuestión clave para la educación del siglo XXI. Instructional Strategies in Teacher Training. Recuperado de https://dialnet.unirioja.es/servlet/articulo?codigo=6157794

George, D. and Mallery, P. (2003). SPSS for Windows step by step: A simple guide and reference, 11.0 update ( $4^{\text {th }}$ ed.). Boston: Allyn \& Bacon. 


\section{Revista Iberoamericana \\ de las Ciencias Sociales y \\ Humanísticas}

ISSN : $2395-7972$

Glasserman, L. y Manzano, J. (2016). Diagnóstico de las habilidades digitales y prácticas pedagógicas de los docentes en educación primaria en el marco del programa $\mathrm{Mi}$ Compu.MX. Apertura, Revista de Innovación Educativa, 8(1). Recuperado de http://www.udgvirtual.udg.mx/apertura/index.php/apertura/article/view/820

Gobierno del Estado de Yucatán (2015). Tabletas electrónicas para todos los estudiantes de educación primaria. Recuperado de http://www.educacion.yucatan.gob.mx/shownoticia.php?id=4119

González, A., Calleja, V., López, L., Padrino, P. y Puebla, P. (2009). Los estudios de encuesta. Métodos de investigación en educación especial. Recuperado de https://www.academia.edu/35078178/LOS_ESTUDIOS_DE_ENCUESTA_AMAND

\section{A_GONZ\%C3\%81LEZ_VANESA_CALLEJA_LETICIA_L\%C3\%93PEZ_PATRICI A_PADRINO_PATRICIA_PUEBLA}

Gutiérrez, A. (2012). Las TIC en la formación del maestro. "Realfabetización" digital del profesorado. Revista Interuniversitaria de Formación del Profesorado, 63(22), 191206. Recuperado de http://www.redalyc.org/html/274/27418813011/

Hernández, R., Fernández, C. y Baptista, P. (2013). Metodología de la investigación (4. ${ }^{a}$ ed.). Distrito Federal, México: McGraw-Hill.

Isaac, S and Michael, W. (1995). Handbook in Research and Evaluation. San Diego California: EDITS, Publishers.

Linarez, G. (2014). Programa "Mi Compu.Mx": alfabetización digital para todos. Revista Iberoamericana de Producción Académica y Gestión Educativa, 1(2), 1-12. Recuperado de http://www.pag.org.mx/index.php/PAG/article/viewFile/216/264

Marchesi, A., Tedesco, J. y Coll, C. (coords.) (2010). Calidad, equidad y reformas en la enseñanza. Madrid: Fundación Santillana. Recuperado de http://www.oei.es/historico/noticias/spip.php?article9238=

Marqués, P. (2012). Impacto de las TIC en la educación: funciones y limitaciones. Revista de Investigación, 1(3), 1-15. Recuperado de https://www.3ciencias.com/wpcontent/uploads/2013/01/impacto-de-las-tic.pdf

Pérez, A. (2010). Nuevas exigencias y escenarios para la profesión docente en la era de la información y de la incertidumbre. Revista Interuniversitaria de Formación del Profesorado, 24(2), 17-36. Recuperado de http://www.redalyc.org/articulo.oa?id=27419198002 


\section{Revista Iberoamericana \\ de las Ciencias Sociales y \\ Humanísticas}

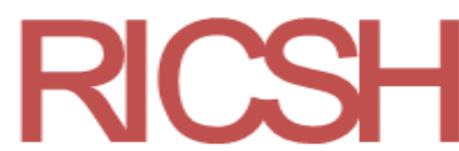

ISSN: 2395 - 7972

Prensky, M. (2001). Digital natives, digital immigrants. On the Horizon, 9(5), 1-6. Retrieved from https://www.marcprensky.com/writing/Prensky\%20\%20Digital\%20Natives,\%20Digital\%20Immigrants\%20-\%20Part1.pdf

Quiñonez, S., Zapata, A. y Canto, P. (2018). Percepción de profesores sobre la afectividad en los entornos virtuales en una universidad pública del sureste de México. Revista Iberoamericana para la Investigación y Desarrollo Educativo, 9(17), 1-30. Doi: https://doi.org/10.23913/ride.v9i17.378

Reyes, W. y Quiñonez, S. (2018). Diagnóstico de competencias en el uso de las TIC por estudiantes de nivel básico. Educación y Ciencia, 7(50), 7-16.

Salinas, J. (coord.) (2008). Innovación educativa y uso de las TIC. Sevilla: Universidad Internacional de Andalucía, España. Recuperado de http://dspace.unia.es/bitstream/handle/10334/2524/innovacioneduc2008.pdf?sequence $=1$

Santiago, G., Caballero, R., Gómez, D. y Domínguez, A. (2013). El uso didáctico de las TIC en escuelas de educación básica en México. Revista Latinoamericana de Estudios Educativos, 43(3), 99-131.

Secretaría de Educación Pública [SEP] (2006). Libro blanco, Programa Enciclomedia 20062012

http://www.sep.gob.mx/work/models/sep1/Resource/2959/4/images/LB\%20Encicloed ia.pdf

Secretaría de Educación Pública [SEP] (2009). Programa: habilidades digitales para todos. Recuperado de http://sep.gob.mx/work/models/sep1/Resource/2959/5/images/LB\%20HDT.pdf

Secretaría de Educación Pública [SEP] (2016). Programa de inclusión digital 2016-2017. Recuperado de https://www.gob.mx/cms/uploads/attachment/file/162354/NUEVO_PROGRAMA_P RENDE_2.0.pdf

Unesco (21 de marzo de 2018). Las competencias digitales son esenciales para el empleo y la inclusión social. Oficina de la UNESCO en Lima. Recuperado de http://www.unesco.org/new/es/media-services/singleview/news/las_competencias_digitales_son_esenciales_para_el_empleo_y_l/

Villegas, M., Mortis, S., García, R. y Del Hierro, E. (2017). Uso de las TIC en estudiantes de quinto y sexto grado de educación primaria. Apertura, 9(1), 50-63. Recuperado de http://www.scielo.org.mx/pdf/apertura/v9n1/2007-1094-apertura-9-01-00050.pdf 


\section{Revista Iberoamericana \\ de las Ciencias Sociales y \\ Humanísticas}

ISSN: 2395 - 7972

Zapata, A., Quiñonez, S. y Canto, P. (2017). Uso de dispositivos móviles en estudiantes de quinto año de primaria. En Torres, H. (presidente). XIV Congreso Nacional de Investigación Educativa. Congreso llevado a cabo en San Luis Potosí, México.

\begin{tabular}{|c|c|}
\hline Rol de Contribución & Autor (es) \\
\hline Conceptualización & Sergio Humberto Quiñonez Pech \\
\hline Metodología & Sergio Humberto Quiñonez Pech \\
\hline Software & $\begin{array}{l}\text { Alfredo Zapata González (principal) } \\
\text { Pedro José Canto Herrera (apoyo) }\end{array}$ \\
\hline Validación & $\begin{array}{l}\text { Sergio Humberto Quiñonez Pech (principal) } \\
\text { Pedro José Canto Herrera (apoyo) }\end{array}$ \\
\hline Análisis Formal & $\begin{array}{l}\text { Sergio Humberto Quiñonez Pech (principal) } \\
\text { Pedro José Canto Herrera (igual) }\end{array}$ \\
\hline Investigación & $\begin{array}{l}\text { Sergio Humberto Quiñonez Pech (principal) } \\
\text { Pedro José Canto Herrera (apoyo) }\end{array}$ \\
\hline Recursos & $\begin{array}{l}\text { Pedro José Canto Herrera (principal) } \\
\text { Sergio Humberto Quiñonez Pech (igual) }\end{array}$ \\
\hline Curación de datos & $\begin{array}{l}\text { Sergio Humberto Quiñonez Pech (principal) } \\
\text { Alfredo Zapata Gonález (igual) }\end{array}$ \\
\hline $\begin{array}{l}\text { Escritura - Preparación del } \\
\text { borrador original }\end{array}$ & Sergio Humberto Quiñonez Pech \\
\hline $\begin{array}{l}\text { Escritura - Revisión y } \\
\text { edición }\end{array}$ & $\begin{array}{l}\text { Sergio Humberto Quiñonez Pech (principal) } \\
\text { Pedro José Canto Herrera (igual) } \\
\text { Alfredo Zapata González (igual) }\end{array}$ \\
\hline Visualización & $\begin{array}{l}\text { Sergio Humberto Quiñonez Pech (principal) } \\
\text { Pedro José Canto Herrera (igual) } \\
\text { Alfredo Zapata González (apoyo) }\end{array}$ \\
\hline Supervisión & Sergio Humberto Quiñonez Pech \\
\hline $\begin{array}{l}\text { Administración de } \\
\text { Proyectos }\end{array}$ & $\begin{array}{l}\text { Sergio Humberto Quiñonez Pech (principal) } \\
\text { Pedro José Canto Herrera (apoyo) } \\
\text { Alfredo Zapata González (apoyo) }\end{array}$ \\
\hline Adquisición de fondos & $\begin{array}{l}\text { Pedro José Canto Herrera (principal) } \\
\text { Alfredo Zapata González (apoyo) } \\
\text { Sergio Humberto Quiñonez Pech (apoyo) }\end{array}$ \\
\hline
\end{tabular}

